\section{Abstract}

\title{
Influence of air-assistance on spray application for tomato plants in
} \section{greenhouses}

\author{
Jordi Llop ${ }^{\mathrm{a}}$, Emilio Gil ${ }^{\mathrm{a}, *}$, Jordi Llorens ${ }^{\mathrm{b}}$, Montserrat Gallart ${ }^{\mathrm{a}}$, Paolo Balsari ${ }^{\mathrm{c}}$ \\ ${ }^{a}$ Universitat Politècnica de Catalunya, Department of Agri Food Engineering and
} Biotechnology, Esteve Terradas 8, Campus del Baix Llobregat D4, 08860 Castelldefels, Barcelona, Spain

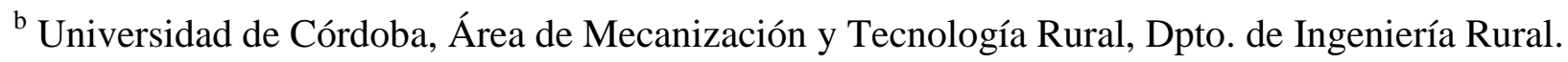
Córdoba 14005, Spain

${ }^{\mathrm{c}}$ Università di Torino, DISAFA, Largo Paolo Braccini, 2, 10095 Grugliasco, Italy * Corresponding author: Prof. Emilio Gil; E-mail: emilio.gil@upc.edu

Protected horticulture production represents one of the most important agricultural businesses in Southern Europe. However, many problems related to the lack of mechanisation, intensive use of pesticides, and, in some cases, undesirable residues on food, have not been solved yet. In this context, application technology is a key factor for the improvement of the efficacy and efficiency of plant protection products. Spray guns and knapsack sprayers are the most common technologies that have been used for this purpose. However, several studies have demonstrated that, compared with spray guns, the use of vertical boom sprayers in greenhouses improves spray

\footnotetext{
Abbreviations: PPP - plant protection products; DISAFA - Dipartimento di Scienze Agrarie, Forestali e Alimentari; LAI - leaf area index; LWA - leaf wall area; TRV - tree row volume; LAD - leaf area density; ANOVA - analysis of variance; HSD - honest significant difference; SEM - standard error of the mean.
} 
19 distribution and reduces labour costs and operator exposure. The main objective of this study

20 was to evaluate the influence of air-assistance on spray application in conventional tomato

21 greenhouses. For this purpose three different spray conceptions were evaluated: 1) a modified

22 commercial handheld trolley sprayer with two air assistance concepts; 2) a self-propelled

23 sprayer; and 3) an autonomous self-propelled sprayer with remote control. All the sprayers

24 considered were evaluated in terms of absolute and normalised canopy deposition, uniformity of

25 distribution, and losses to the ground. In addition, the vertical liquid and air velocity distributions

26 of the sprayers were assessed and compared with the canopy profiles and spray depositions.

27 Yellow tartrazine (E-102 yellow) was used as a tracer for deposition evaluation. The results

28 indicated that increasing the air velocity does not increase the efficiency of a spray application.

29 In general, the modified handheld trolley sprayer showed the best results in terms of deposition

30 and uniformity of distribution, especially at the lowest air assistance rate. These results were

31 confirmed with evaluation of the uniformity of the air and liquid distribution.

33 Keywords: Handheld trolley sprayer, air assistance, vertical pattern, air velocity, spray

34 deposition

\section{1. Introduction}

37 One of the most hazardous factors affecting the economic, environmental and productivity 38 parameters in protected horticultural production involves the use of plant protection products 39 (PPP) for pest/disease control. Operator safety, residues on produced food, environmental 40 contamination and economic investment are the problems related to this specifically as well as 
41 labour requirements, and most of them are directly linked to the technology used during the

42 process (Nilsson and Balsari, 2012). At the same time, covered horticulture production

43 represents one of the most important agricultural businesses in Southern Europe, focused mainly

44 in Spain, Italy, and France (EFSA, 2010). However, many unsolved problems exist related to the

45 lack of mechanisation, intensive use of PPPs (Nuyttens et al., 2004a; Céspedes et al., 2009), and

46 undesirable residues on food (van Os et al., 2005).

47 In recent years, there have been important improvements in spray technology, with considerable

48 differences depending on the target crops. Manufacturers of field crop and orchard sprayers have

49 progressively introduced new and improved devices, taking advantage of the latest developments

50 in computers, electronics, and global positioning systems. Those improvements have led to a

51 safer and more effective use of pesticides, reducing the risk of contamination, adapting the

52 proper dose to the canopy structure (Gil et al., 2007, 2011; Siegfried et al., 2007; Zhou et al.,

53 2012) and improving traceability. However, the improvements have not been implemented as

54 quickly in the case of spray application techniques used in greenhouses, where handheld sprayers

55 or knapsack sprayers are still very popular (Nuyttens et al., 2004b; Balloni et al., 2008; Nilsson

56 and Balsari, 2012; Sánchez-Hermosilla et al., 2013). The use of such primary technologies leads

57 to limited efficacy and efficiency of pesticide application, with high risk of operator exposure

58 (Nuyttens et al., 2009).

59 Alternative spraying techniques to handheld sprayers have been developed and tested in the past

60 few years. Several studies have already demonstrated that the use of vertical boom sprayers in

61 greenhouses improves spray distribution (Nuyttens et al., 2004a; Sánchez-Hermosilla et al.,

62 2012) and reduces labour costs and operator exposure (Nuyttens et al., 2004b, 2009) in

63 comparison with spray guns. Other researchers have investigated automatic spraying on PPP 
64 using new technologies such as navigation systems and autonomous vehicles with ultrasonic

65 sensors or machine vision (Mandow et al., 1996; Sammons et al., 2005; Subramanian et al.,

66 2005; González et al., 2009; Balsari et al., 2012; Sánchez-Hermosilla et al., 2013). However,

67 according to Sánchez-Hermosilla et al. (2012), the use of such vehicles is very limited because of

68 the high costs involved.

69 Air assistance has been considered one of the key elements for improving the efficiency of the 70 spray application process in greenhouses, especially for dense crops (Llop et al., 2015). Derksen

71 et al. (2007) achieved higher spray coverage on lower surfaces of bell pepper leaves using air-

72 assisted delivery with single-fan nozzles than when using conventional delivery with either twin-

73 fan or air induction nozzles. Similar results were obtained by Braekman et al. (2010) and

74 Abdelbagi and Adams (1987). However, although air assistance has proven to be important for

75 improving deposition on the canopy, it is still necessary to investigate the air distribution

76 according to the canopy structure and the optimal relationship between the vertical distributions

77 of the three factors affecting deposition, namely canopy surface, air velocity profile, and liquid

78 distribution. Improvements in the uniformity of deposition have been achieved through optimum

79 relationships between those parameters in several vertical crops such as vineyards (Pergher and

80 Gubiani, 1995; Gil et al., 2013), citrus (Pai et al., 2009; Khot et al., 2012), and orchards (Landers

81 et al., 2012).

82 Along with the new and improved technologies, the working parameters selected for the spray

83 application processes (mainly volume rate and pressure) are also important factors affecting the

84 final success. A survey of greenhouse farmers in the Netherlands (Goossens et al., 2004) showed

85 that $90 \%$ of growers used high-pressure spray equipment (i.e. spray guns or lances) to apply

86 PPPs, even though spray boom equipment has become increasingly popular. Braekman et al. 
87 (2009) confirmed that growers were convinced that high application rates and spray pressures are

88 indispensable for obtaining satisfactory coverage and sufficient penetration. Moreover, van

89 Zuydam and van de Zande (1996) reported that the condition of the average spraying equipment

90 used in daily practice is variable and usually not of a high standard.

91 The main objective of this research was to investigate the effect of air-assistance on different 92 spray application techniques, ranging from manually pulled trolley sprayers to autonomous

93 sprayers, on the spray deposition on tomato plants grown in greenhouses. Additionally, the effect

94 of air velocity and nozzle pattern on canopy deposition, uniformity, and losses to the soil were 95 also assessed.

\section{2. Materials and methods}

\section{2.1. Spraying equipment}

99 Three air-assisted sprayers adapted to greenhouse conditions were tested (Fig. 1). These three 100 sprayers were used for four independent treatments as the first sprayer, a research prototype 101 derived from a commercial handheld trolley sprayer, was converted into two different versions 102 equipped with different blower units. Consequently, four different treatments (T1 to T4) were 103 tested.

104 [insert Fig.1]

105 Fig. 1. Sprayers tested during trials: a) modified sprayer $-\mathrm{T} 1$; b) modified sprayer $-\mathrm{T} 2$; c) 106 Sagevi sprayer - T3; d) Unigreen sprayer - T4 
109 The modified prototype T1 was a modification of a commercial handheld trolley sprayer

110 (Carretillas Amate, Almería, Spain) with two vertical booms that could be adjusted to the canopy

111 width and had six nozzles per side spaced at $0.35 \mathrm{~m}$ intervals. This modified sprayer (Fig. 1a)

112 was fitted with an air-assistance device (average air velocity of $19.3 \mathrm{~m} \mathrm{~s}^{-1}$ ) composed of an air

113 generator (Nuvola 5HP, Cifarelli S.P.A., Voghera, Italy) activated by a $3.68 \mathrm{~kW}$ engine, a central

114 air collector, and six individual spouts fitted parallel to each nozzle.

115 The modified prototype T2 (Fig. 1b) consisted of the same handheld sprayer as previously 116 mentioned, but equipped with a different blower (B\&D 3000W, Stanley Black \& Decker Inc.,

117 New Britain, UK) with an air velocity of $14.0 \mathrm{~m} \mathrm{~s}^{-1}$ (average of values measured at each air 118 outlet surface). This blower had an electric engine connected to a cable attached to the feeding 119 pipe following the specifications described by Llop et al. (2015).

120 Both sprayers ( $\mathrm{T} 1$ and $\mathrm{T} 2$ ) were fed using a pipe connected to an external sprayer through a 121 piston pump with a tank of 100 L capacity.

123 A self-propelled sprayer Atom 120 (Sagevi, Vilassar de Dalt, Spain), with air assistance, 120 L

124 tank capacity, and four nozzles per side mounted in pairs, was also tested (Fig. 1c). The first pair 125 of nozzles was located $0.59 \mathrm{~m}$ from the ground, and the second one was on an adjustable mast 126 with a height range of $1-2 \mathrm{~m}$ that could be varied using a hydraulic piston activated by the 127 operator. The distance between the two pairs of nozzles was $0.7 \mathrm{~m}$, and the nozzles were fitted 128 inside individual air outlets. 
131 A Unigreen self-propelled sprayer mounted on a platform with remote control, developed in 132 collaboration with Unigreen (Maschio Gaspardo S.p.A., Campodarsego, Italy) and DISAFA 133 (Dipartimento di Scienze Agrarie, Forestali e Alimentari) (University of Turin, Italy), was also 134 selected for the field trials. The prototype (Fig. 1d), described in detail in Balsari et al. (2012), 135 has a 150 L capacity tank with two vertical booms and four nozzles on each side located at 0.45

136 m intervals. The air-assistance device consisted of an electric axial fan blower connected to a 137 vertical air sleeve with several outputs per side.

\section{8}

139

140

141

142

143

$144 \mathrm{~m}$ distance between plants in a row, and $0.8 \mathrm{~m}$ between twin plants. The canopy was 145 characterised by measuring the whole leaf area of three pairs of randomly selected plants. The 146 values of leaf area index (LAI) were determined by adapting the area/weight ratio protocol, as 147 described in previous work (Cross et al., 2001; Gil et al., 2007; Llorens et al., 2010; Llop et al., 148 2015). Geometric parameters (canopy height and canopy width) and derived parameters (leaf 149 wall area (LWA), tree row volume (TRV), and leaf area density (LAD)) were also calculated.

\subsection{Canopy characterisation}

The experiments were conducted at Viladecans (Barcelona, NE Spain) in a commercial tomato (Solanum lycopersicum L. cv. Barbastro) greenhouse of $1265 \mathrm{~m}^{2}$ (composed of a main corridor with several aisles on each side) located in a typical field farming area of this region.

The tomato plants had an average canopy height of $1.96 \mathrm{~m}$ and average width of $1.07 \mathrm{~m}$. The plants were dispersed in a twin row system (two plants close together) with $2 \mathrm{~m}$ aisle width, 0.4 
151 The sprayers were evaluated in terms of absolute and normalised canopy deposition, uniformity

152 of distribution over the whole canopy, and losses to the ground. In order to quantify the amount

153 of tracer deposited on the canopy, four masts were mounted, two in between the twin plants and

154 two outside (Fig. 2). Each mast was divided into three vertical areas (top, middle, and bottom)

155 covering the total height of the canopy and resulting in 12 sampling zones for each replication.

156 Filter paper pieces of $24 \mathrm{~cm}^{2}$ surface $(3 \times 8 \mathrm{~cm})$ (Filtros Anoia S.A., Barcelona, Spain) were used

157 as collectors and placed on dedicated paper clips previously fixed on the masts. The collectors

158 were positioned horizontally. To evaluate the losses to the ground, four filter strip pieces were

159 placed on wooden supports, two in the middle of the row (one per side) and two under the

160 canopy. Due to the difficulty of completely randomising the sampling zones, nine replicates

161 containing all the sampling protocol were settled along the same canopy row of $23.4 \mathrm{~m}$, with a

162 minimum distance of $2 \mathrm{~m}$ between replicates. Gil (2001), Llorens et al. (2010) and Llop et al.

163 (2015) used similar arrangements. The sprayers passed along the row spraying the canopy from

164 both sides. After every test, all the samples (filter papers) were carefully collected, placed in

165 tagged plastic bags, and stored in a dark container. During the trials, the recorded values of 166 temperature and humidity ranged from $25^{\circ} \mathrm{C}$ to $30^{\circ} \mathrm{C}$ and from $60 \%$ to $70 \%$.

167 [insert Fig. 2]

168 Fig. 2. Sampling protocol. Positions of collectors on the canopy by height (top, middle, and 169 bottom), by depth (external and internal), and on the ground (AL: aisle left, CL: canopy left, CR: 170 canopy right, AR: aisle right)

171 2.4. Adjustment of working parameters of sprayers 
172 The spray conditions selected for the three sprayers in the four tests are shown in Table 1. The 173 sprayers were adjusted for an application rate of $800 \mathrm{~L} \mathrm{ha}^{-1}$ following grower recommendations.

174 It is worth noting that, with the self-propelled sprayer (Unigreen), problems relating to the 175 efficiency of the electric batteries made it difficult to reach a pressure up to 1.5 bar during the 176 trial and, consequently, it was not possible to reach the intended volume rate, resulting on an 177 applied volume of $613 \mathrm{~L} \mathrm{ha}^{-1}$.

178 All the sprayers were fitted with the conventional flat fan nozzles XR11003 (Spraying Systems 179 Co., TeeJet Technologies, Illinois, USA). The working pressure (in the range $1.5-3.0 \times 10^{2} \mathrm{kPa}$ ) 180 was established following the recommendations of the nozzle manufacturer, and the forward 181 speed $\left(3.5 \mathrm{~km} \mathrm{~h}^{-1}\right)$ was selected and measured to be a comfortable speed for the operator. The 182 forward speed was measured recording the time used to travel a known distance. Prior to each 183 test, the flow rate of the nozzles was measured using a mechanical nozzle flow meter (A.A.M.S. $184 \mathrm{NV}$, Meldegem, Belgium) and the pressure was measured with a tested manometer at the 185 entrance of the section.

186 The configuration of each sprayer (nozzle number, nozzle orientation, and boom height) was 187 individually adjusted according to the canopy characteristics in order to match the whole canopy 188 as much as possible, while avoiding losses to the soil or over the top of the canopy. In the case of 189 the handheld modified sprayers (T1 and T2), the lowest nozzle, placed at $0.3 \mathrm{~m}$ from the ground, 190 was closed to adjust the spray pattern to the canopy profile. In the case of the Sagevi sprayer 191 (T3), the height of the top pair of nozzles was adjusted to $1.8 \mathrm{~m}$. It was not possible to close the 192 lowest pair of nozzles because of the characteristics of the particular sprayer. The nozzle setting 193 on the Unigreen (T4) sprayer was also adjusted considering the canopy structure and the sprayer 
194 characteristics. The bottom nozzle was placed at $0.46 \mathrm{~m}$ from the ground, and the highest nozzle 195 was at a height of $1.66 \mathrm{~m}$ from the ground.

\subsection{Characterisation of sprayers}

197 Before the spray tests, each sprayer was characterised in terms of air velocity and liquid spray 198 pattern distribution. To evaluate the air velocity profile, a 3D ultrasonic anemometer (Gill 199 instruments, Hampshire, United Kingdom) was used. The air speed was assessed perpendicular 200 to the main air direction, simulating the canopy position in relation to the pass of the sprayer. 201 Measurements for the modified sprayer ( $\mathrm{T} 1$ and $\mathrm{T} 2$ ) were obtained at vertical intervals of $0.1 \mathrm{~m}$ 202 at distances of $0.14 \mathrm{~m}, 0.2 \mathrm{~m}, 0.3 \mathrm{~m}$ and $0.4 \mathrm{~m}$ from the air outlet. This methodology is an 203 adaptation of the method described by García-Ramos et al. (2012). In the case of the Sagevi and

204 Unigreen sprayers, measurements were obtained at vertical intervals of $0.1 \mathrm{~m}$ at the distances of $2050.2 \mathrm{~m}, 0.3 \mathrm{~m}$, and $0.4 \mathrm{~m}$ from the air outlet; the distance of $0.14 \mathrm{~m}$ was not possible because of 206 the dimensions of the anemometer and the design of air outlet. For all the sprayers, three 207 replicates were performed for each measurement position. Data from the anemometer were 208 interpolated to obtain the air distribution map using the filled.contour function of the software $\mathrm{R}$ 209 (Murrell, 2005). Additionally, the air velocity at each outlet surface was measured using a 210 portable impeller anemometer (Lambrecht Meteodigit I 14163, Lambrecht meteo GmbH, 211 Göttingen, Germany).

212 The spray pattern liquid distribution was evaluated using a vertical patternator (A.A.M.S. NV, 213 Meldegem, Belgium), which was placed at $0.3 \mathrm{~m}$ distance from the sprayer. The spray collectors 214 on the vertical patternator were placed at vertical intervals of $0.2 \mathrm{~m}$. Three repetitions were 215 carried out for each sprayer. Results have been expressed as a percentage of total liquid 
216 recovered at each collector by height position following the models purposed by (Pergher et al.,

217 2002; Balsari et al., 2007; Gil et al., 2013).

218 2.6. Analysis of samples

219 Yellow Tartrazine (E-102 yellow) mixed in the tank was used as a tracer in all the trials.

220 Tartrazine was selected for the easy sample methodology in the laboratory, the high recovery

221 rate of the tracer and the reasonable low photodegradation (Pergher, 2001). In addition, this

222 product has been used as a tracer by several researchers (Sánchez-Hermosilla et al., 2011; Balsari

223 et al., 2012; Gil et al., 2014). For the extraction of the tracer, $20 \mathrm{~mL}$ of deionised water was

224 added in the plastic bag, and after 1 min of mixing, a sample was extracted and measured with a 225 colorimeter (Thermo Scientific Genesys 20, Thermo Fisher Scientific Inc., Waltham, USA) at a 226 wavelength of $427 \mathrm{~nm}$. At the beginning and end of each trial, a sample from the tank (Table 3) 227 was obtained at the output of the nozzle in order to normalise the deposit.

228 The amount of tracer deposited on the sample (canopy and soil) was calculated considering the 229 water solution volume to extract the tracer and the area of the collector according Llorens et al. 230 (2010) and Gil et al. (2007) as it shows equation 1:

$$
d=\frac{T_{c l} \times w}{S_{a}}
$$

233 where $d$ is the tracer concentration per unit sample surface $\left(\mu \mathrm{g} \mathrm{cm}{ }^{-2}\right), T_{c l}$ is the tracer 234 concentration of the sample $\left(\mathrm{mg} \mathrm{L}^{-1}\right), w$ is the amount of water used to extract the tracer from the 235 sample $(\mathrm{mL})$ and $\mathrm{S}_{\mathrm{a}}$ is the area exposed of the sample $\left(\mathrm{cm}^{2}\right)$. 
236 Since the tracer application rates $\left(T_{c s}\right)$ were not the same for all treatments, a normalised deposit,

$237 d_{n}\left(\mu \mathrm{g} \mathrm{cm}^{-2}\right.$ sample $/ \mu \mathrm{g} \mathrm{cm}^{-2}$ ground $)$, was calculated according to Eq. (2) by dividing the deposit $d$ by 238 the amount of tracer applied per unit ground area, following similar previously described 239 procedures (Cross et al., 2001; Gil et al., 2011; Siegfried et al., 2007; Viret et al., 2003). The 240 normalised deposit enables comparisons between the different sprayers and it is represented by 241 equation 2:

$$
d_{n}=\frac{d \times 10^{5}}{V \times T_{c s}}
$$

243 where $d_{n}$ is the normalised deposit $\left(\mu \mathrm{g} \mathrm{cm}^{-2}\right.$ sample $\left./ \mu \mathrm{g} \mathrm{cm}{ }_{\text {ground }}\right), d$ is the tracer concentration per

244 unit sample surface $\left(\mu \mathrm{g} \mathrm{cm}^{-2}\right), V$ is the volume rate application $\left(\mathrm{L} \mathrm{ha}^{-1}\right)$ and $T_{c s}$ is the tracer 245 concentration of the tank for each treatment $\left(\mathrm{mg} \mathrm{L}^{-1}\right)$. Table 3 show the main values of absolute 246 and normalized deposition of every test.

\section{2.7. Statistical analysis}

248 Statistical analysis was performed using the statistical software R (R Development Core Team, 249 2013). The effects of the different sprayers on canopy and soil deposition were examined using 250 one-way analyses of variance (ANOVA), followed by the Tukey HSD (honest significant 251 difference) post-hoc test for multiple comparisons. Before statistical analysis, the assumptions of 252 ANOVA were checked.

\section{3. Results and discussion}

\subsection{Canopy characterisation}


256 The results of canopy characterisation are summarised in Table 2. High values of the calculated

257 parameters (e.g. high crop density) indicated particular difficulties regarding pesticide

258 application on this type of crop. In addition, from the ground to a height of $0.34 \mathrm{~m}$, the tomato

259 crop had no leaves.

261 The results of air velocity measured at each outlet (Table 1) provide a general overview of the air

262 performance. The highest value was obtained for the Sagevi sprayer $\left(31.3 \mathrm{~m} \mathrm{~s}^{-1}\right)$, and the lowest

263 for the Unigreen sprayer $\left(10.08 \mathrm{~m} \mathrm{~s}^{-1}\right)$. The air velocities of the modified sprayers $\mathrm{T} 1$ and $\mathrm{T} 2$

264 were $19.3 \mathrm{~ms}^{-1}$ and $14.0 \mathrm{~ms}^{-1}$, respectively.

265 The detailed air velocity distribution obtained for each sprayer is shown in Fig. 3. In general, the

266 modified sprayers (T1 and T2) produced similar air distributions, although the air velocities

267 measured with the ultrasonic anemometer were lower for T2 $\left(\sim 3.5 \mathrm{~m} \mathrm{~s}^{-1}\right)$ than for T1 $\left(\sim 5.5 \mathrm{~m} \mathrm{~s}^{-1}\right)$

268 because of the difference in the air blower unit. In both cases, the plume of air was almost

269 perpendicular to the vertical plane of the canopy, making it possible to identify the directions of

270 individual jets, similar to the case in Dekeyser et al. (2013) for orchard sprayers. Moreover, the

271 air velocity measurements at the top and bottom air jets were lower than those measured at the

272 other four jets. This behaviour was similar for both sprayers (T1 and T2) but with different air

273 velocity values. For the Sagevi sprayer (T3), three air areas could be clearly distinguished. At the

274 bottom part of the sprayer, the highest values of air velocity were obtained $\left(\sim 6 \mathrm{~m} \mathrm{~s}^{-1}\right)$, whereas at

275 the central zone of the sprayer, the air velocity was almost zero. At the top of the sprayer, the air

276 velocities generated were lower than those measured at the bottom and had a crosswise direction,

277 whereas the bottom air direction was perpendicular to the canopy. The air distribution of the

278 Unigreen sprayer (T4) was more homogeneous than the rest, but the velocity values were lower 
279 (always less than $3 \mathrm{~m} \mathrm{~s}^{-1}$ ). Differences observed in the zones were probably caused by the 280 spraying system performance.

$281 \quad$ [insert Fig. 3]

282 Fig. 3. Air velocity $\left(\mathrm{m} \mathrm{s}^{-1}\right)$ distributions of the sprayers tested: a) modified sprayer $-\mathrm{T} 1$; b) 283 modified sprayer - T2; c) Sagevi sprayer - T3; d) Unigreen sprayer - T4. Arrow size and 284 background colours represent air velocity. Arrows also indicate the main air direction

\subsection{Spray liquid vertical distribution}

286 The spray liquid profile distributions of the four tested sprayers obtained from the vertical 287 patternator are presented in Fig. 4. The modified sprayers (T1 and T2) generated similar profile 288 distributions because they had the same nozzle distribution on the vertical boom. In this case, the 289 aforementioned differences in air velocity did not affect the liquid distribution. However, these 290 results are not in accordance with those obtained by Khot et al. (2012), which indicated that, at 291 higher air velocities, more liquid was retained by the vertical patternator.

$292 \quad$ [insert Fig. 4]

293 Fig. 4. Liquid distribution represented as percentage of spray recovered of each sprayer: a) 294 modified sprayer - T1; b) modified sprayer - T2; c) Sagevi sprayer - T3; d) Unigreen sprayer 295 T4. Mean \pm standard error of the mean (SEM) are represented. Bars mean \pm SEM of the data.

297 The Sagevi sprayer (T3) showed a deficit of spray liquid between $0.7 \mathrm{~m}$ and $0.11 \mathrm{~m}$ and an 298 excess at the heights near the ground. The liquid distribution of the Unigreen sprayer (T4) only 299 reached $1.8 \mathrm{~m}$, because the last spraying nozzle was mounted at $1.66 \mathrm{~m}$, and was almost 300 continuous in the vertical profile. Overall, considering the spray liquid distributed to the canopy 
301 profile (from $0.34-2.3 \mathrm{~m}$ ), T1 and T2 were found to be best adapted mostly due to the height 302 position of the top nozzle. Other studies (Derksen and Gray, 1995; Gil et al., 2013) have 303 emphasised the importance of adjusting the vertical spray profile to the canopy characteristics in 304 order to achieve adequate spray application.

305 The high uniformity in vertical liquid distribution obtained for T1 and T2 can be linked to the 306 number of nozzles placed on the boom and, consequently, to the shortest distance between them.

307 This factor was also deduced by Llop et al. (2015).

308 3.4. Canopy deposition

309 A general overview of canopy deposition (Table 3) indicates that T2 provided the highest values 310 of deposition and uniformity over the canopy. T4 presented the lowest canopy deposition but 311 with no statistical difference compared with T3. These results are in accordance with those 312 obtained by Dekeyser et al. (2013), who postulated that individual spouts result in higher 313 deposits than axial sprayers.

314 A detailed analysis of the canopy deposition showed that, in general and for all the sprayers 315 tested, the average of the deposition values measured at the external sides of the plants was at 316 least 2.5 times higher than the deposition at the internal sides. Moreover, the deposit at the top 317 level was lower than those measured at the middle and bottom sample level, for all the tested 318 sprayers (Fig. 5). The relation between the average deposition values at the internal and external 319 sides was similar for all the treatments. These results (40\%) are similar to those obtained by 320 Sánchez-Hermosilla et al. (2012) (44\%), even though the applied volume rate was doubled in 321 this study.

322 [insert Fig. 5] 
323 Fig. 5. Normalized deposition on the canopy collectors $\left(\mu \mathrm{g} \mathrm{cm}_{\text {sample }}^{-2} \mu \mathrm{g} \mathrm{cm}_{\text {ground }}\right.$ ) for each 324 sprayer: a) modified sprayer - T1; b) modified sprayer - T2; c) Sagevi sprayer - T3; d) Unigreen 325 sprayer - T4. Same letter (by treatments) means no significant differences $(\mathrm{P}<0.05)$. Bars 326 means \pm SEM of the data

328 The external depositions of the sprayers were found to be in the order: $\mathrm{T} 2>\mathrm{T} 1 \geq \mathrm{T} 3 \geq \mathrm{T} 4$ with 329 significant differences between T2 and the rest of the treatments (Table 4). In terms of internal 330 deposition, no significant differences were detected between T1, T2, and T3 (mean of $0.10 \mu \mathrm{g}$ $\left.331 \mathrm{~cm}^{-2}\right)$, whereas T4 presented a significantly lower value $\left(0.05 \mu \mathrm{g} \mathrm{cm}{ }^{-2}\right)$ respect $\mathrm{T} 2$.

332 A detailed evaluation of the results obtained for $\mathrm{T} 1$ and $\mathrm{T} 2$ indicated that higher air velocity does 333 not imply higher spray deposition, and the sprayer with highest air velocity (T3) showed less 334 deposition than sprayer T2. Furthermore, T1 and T2 presented more deposition at the top canopy 335 level because of the position of the top nozzle, as shown in Fig. 4, which demonstrates that the 336 high positions of those sprayers lead to more liquid recovery.

337 The importance of adjusting the vertical liquid distribution and air distribution according to the 338 canopy structure has been widely demonstrated in previous studies (Derksen and Gray, 1995; 339 Pergher et al., 1997). The results obtained in this research showed that T3 and T4, which 340 delivered the most heterogeneous vertical liquid distribution and air distribution, also generated 341 the greatest differences in canopy deposition between the sampling zones, especially in the 342 external part of the canopy (Figs. 4 and 5). Treatments T1 and T2, which generated a more-

343 homogeneous vertical distribution (air velocity and liquid), provided the most-uniform spray 344 deposition on the canopy according to the coefficient of variation (Table 3 ). The obtained results 345 also demonstrated that higher air velocity does not imply better liquid distribution or higher spray 
346 deposition, penetration, and uniformity. In general, $\mathrm{T} 1$ and $\mathrm{T} 2$, which had low air velocities but

347 the most-uniform distributions, demonstrated the highest adaptabilities to the canopy. These

348 results are in concordance with those obtained by Cross et al. (2003).

\section{3.5. Losses to the soil}

350 In terms of ground losses, measured as average deposition on the ground, there were no 351 significant differences between the sprayers (Table 3).

352 The distribution of the losses to the soil was similar for all the treatments. The maximum 353 deposition was measured on the samples placed under the crop (Fig. 6), whereas the losses 354 detected in the middle aisle were less than $0.03 \mu \mathrm{g} \mathrm{cm}^{-2}$, except for T3 for which the amount of 355 deposition was significantly the highest $\left(0.09 \mu \mathrm{g} \mathrm{cm}^{-2}\right)$. This tendency can be explained by the 356 high air velocity of this sprayer (Fig. 3)., which could push the spray across the canopy, thereby 357 increasing the losses to the soil In general, the tracer deposits under the canopy were high, 358 sometimes similar to the deposits at the canopy collectors. This may be because there was no 359 vegetation close to the ground (from ground level to $0.5 \mathrm{~m}$ ). In the case of T4, the losses under 360 the canopy were considerably higher, mainly because of the position of the lowest nozzle $(0.45 \mathrm{~m}$ 361 above the ground), which probably directed the spray pattern to the ground.

362 [insert Fig. 6]

363 Fig. 6. Normalized deposition on the ground collectors $\left(\mu \mathrm{g} \mathrm{cm}_{\text {sample }}^{-2} \mu \mathrm{g} \mathrm{cm}_{\text {ground }}\right)$ for each

364 sprayer: a) modified sprayer - T1; b) modified sprayer - T2; c) Sagevi sprayer - T3; d) Unigreen 365 sprayer - T4. AL: aisle left, CL: canopy left, CR: canopy right, AR: aisle right. Same letter (by 366 treatments $)$ means no significant differences $(\mathrm{P}<0.05)$. 
368 From the results, it was identified that losses to the soil are important compared with the 369 deposition on the canopy for this particular case of tomato greenhouses with narrow layouts. 370 Independent of the sprayer, nozzle configuration, and air velocity, the deposits on the soil under 371 the canopy represent an important source of contamination. This fact could be attributed to the 372 high-applied volume rate with respect to the canopy characteristics and density (see Table 1). 373 However, this value was chosen according to the most representative value for the zone.

374 In conclusion, the results of the field tests conducted for the evaluation of different spray 375 technologies in tomato greenhouses emphasise some important aspects:

376 - On sprayers T1 and T2, there was no effect of the air velocity on vertical liquid 377 distribution made with vertical patternator.

378 - Even when air assistance was used, there was a great variability between external and 379 internal deposition, considering the different canopy sections. The deposition at internal 380 part of the canopy was at least 2.5 times lower than external side, highlighting the 381 difficulty to penetrate at the internal side of the canopy.

382 - The modified spray hand held trolley T2 show the highest values in terms of deposition 383 with an air speed of $14 \mathrm{~m} \mathrm{~s}^{-1}$. However, increasing the air velocity did not increase the $384 \quad$ efficiency of the spray application.

$385 \quad-\quad$ Air velocity and vertical spray pattern significantly affected the pesticide distribution on 386 the canopy. The determination these parameters was a useful tool to assess the spray 387 distribution on the canopy. In general the ground losses were relatively high even in some 388 cases can be higher than the canopy deposition revealing the high risk of ground 389 contamination. As concluded by some other researchers (Balsari et al., 2008; Khot et al., 

2012), there is a need to establish an appropriate relationship between the air characteristics (air velocity) and the canopy, even for greenhouse crops.

392 Considering the importance of greenhouse production in the area, there is a need to improve 393 the pesticide application process, which is still hindered by a lack of advanced technologies, 394 compared with other agricultural sectors.

\section{Acknowledgments}

397 This research was developed under the chair Syngenta-UPC. The authors would like to thank 398 Prof. García-Ramos from University of Zaragoza and the collaborator farmer, Mr. Calbet, for his 399 help.

400

401 References

402 Abdelbagi, H.A., Adams, A.J., 1987. Influence of droplet size, air-assistance and electrostatic 403 charge upon the distribution of ultra-low-volume sprays on tomatoes. Crop Prot. 6, 226$404 \quad 233$. doi:10.1016/0261-2194(87)90043-3.

405 Balloni, S., Caruso, L., Cerruto, E., Emma, G., Schillaci, G., 2008. A prototype of self-propelled 406 sprayer to reduce operator exposure in greenhouse treatment. In: Innovation Technology to 407 Empower Safety, Health and Welfare in Agriculture and Agro-Food Systems, 15-17 408 September 2008, Ragusa, Italy. 
409

410

411

412

413

414

415

416

417

418

419

420

421

422

423

424

425

426

Balsari, P., Gioelli, F., Tamagnone, M., 2007. A new vertical patternator for the determination of vertical spray pattern. In: Second European Workshop on Standardised Procedure for the Inspection of Sprayers in Europe - SPISE 2, 10-12 April, 2007, Straelen, Germany.

Balsari, P., Marucco, P., Oggero, G., Tamagnone, M., 2008. Study of optimal air velocities for pesticides application in vineyard. Asp. Appl. Biology 84, 417-423

Balsari, P., Oggero, G., Bozzer, C., Marucco, P., 2012. An autonomous self-propelled sprayer for safer pesticide application in glasshouse. Asp. Appl. Biol. 114, 197-204.

Braekman, P., Foqué, D., Van Labeke, M.-C., Pieters, J.G., Nuyttens, D., 2009. Influence of spray application technique on spray deposition in greenhouse ivy pot plants grown on hanging shelves. HortScience 44, 1921-1927.

Braekman, P., Foque, D., Messens, W., Van Labeke, M.C., Pieters, J.G., Nuyttens, D., 2010. Effect of spray application technique on spray deposition in greenhouse strawberries and tomatoes. Pest Manag. Sci. 66, 203-212. doi:10.1002/ps.1858.

Céspedes, A.J., García, M.C., Pérez, J.J., Cuadrado, I.M., 2009. Caracterización de la Explotación Hortícola Protegida Almeriense, pp. 177.

Cross, J.V., Walklate, P.J., Murray, R.A., Richardson, G.M., 2001. Spray deposits and losses in different sized apple trees from an axial fan orchard sprayer: 1. Effects of spray liquid flow rate. Crop Prot. 20, 13-30. doi:10.1016/S0261-2194(00)00046-6. 
427 Cross, J.V., Walklate, P.J., Murray, R.A., Richardson, G.M., 2003. Spray deposits and losses in 428 different sized apple trees from an axial fan orchard sprayer: 3. Effects of air volumetric 429 flow rate. Crop Prot. 22, 381-394. doi:10.1016/S0261-2194(02)00192-8.

430 Dekeyser, D., Duga, A.T., Verboven, P., Endalew, A.M., Hendrickx, N., Nuyttens, D., 2013. 431 Assessment of orchard sprayers using laboratory experiments and computational fluid 432 dynamics modelling. Biosyst. Eng. 114, 157-169. 433 doi:10.1016/j.biosystemseng.2012.11.013.

434 Derksen, R.C., Gray, R.L., 1995. Deposition and air speed patterns of air-carrier apple orchard 435 sprayers. Trans. ASABE 38, 5-11. doi:10.13031/2013.27805.

436

437

438

439

440

441

442

443

444

Derksen, R.C., Vitanza, S., Welty, C., Miller, S., Bennett, M., Zhu, H., 2007. Field evaluation of application variables and plant density for bell pepper pest management. Trans. ASABE 50, 1945-1953.

EFSA Panel on Plant Protection Products and their Residues (PPR), 2010. Scientific opinion on emissions of plant protection products from greenhouses and crops grown under cover : outline for a new guidance. EFSA J. 8, 1567-1610. doi:10.2903/j.efsa.2010.1567.

García-Ramos, F.J., Vidal, M., Boné, A., Malón, H., Aguirre, J., 2012. Analysis of the airflow generated by an air-assisted sprayer equipped with two axial fans using a 3D sonic anemometer. Sensors (Basel). 12, 7598-7613. doi:10.3390/s120607598. 
445 Gil, E., 2001. Metodología y criterios para la selección y evaluación de equipos de aplicación de 446 fitosanitarios para la viña. Unpublished Ph.D. Dissertation. Universitat de Lleida, 447 Department of Agroo Forest Engineering.

448 Gil, E., Escolà, A., Rosell, J.R., Planas, S., Val, L., 2007. Variable rate application of plant 449 protection products in vineyard using ultrasonic sensors. Crop Prot. 26, 1287-1297. 450 doi:10.1016/j.cropro.2006.11.003.

451 Gil, E., Llorens, J., Landers, A., Llop, J., Giralt, L., 2011. Field validation of DOSAVIÑA, a 452 decision support system to determine the optimal volume rate for pesticide application in 453 vineyards. Eur. J. Agron. 35, 33-46. doi:10.1016/j.eja.2011.03.005.

454 Gil, E., Landers, A., Gallart, M., Llorens, J., 2013. Development of two portable patternators to 455 improve drift control and operator training in the operation of vineyard sprayers. Span. J. 456 Agric. Res. 11, 615-625. doi:10.5424/sjar/2013113-3638.

457 Gil, E., Balsari, P., Gallart, M., Llorens, J., Marucco, P., Andersen, P.G., Fàbregas, X., Llop, J., 458 2014. Determination of drift potential of different flat fan nozzles on a boom sprayer using a 459 test bench. Crop Prot. 56, 58-68. doi:10.1016/j.cropro.2013.10.018.

460 González, R., Rodríguez, F., Sánchez-Hermosilla, J., Donaire, J.G., 2009. Navigation techniques 461 for mobile robots in greenhouses. Appl. Eng. Agric. 25, 153-165. 462 doi:10.13031/2013.26324.

463 Goossens, E., Windey, S., Sonck, B., 2004. Information service and voluntary testing of spray 464 guns and other types of sprayers in horticulture. Asp. Appl. Biol. 71, 41-81. 
465

466

467

468

469

470

471

472

473

474

475

476

477

478

479

480

481

482

483

484

Khot, L.R., Ehsani, R., Albrigo, G., Larbi, P.A., Landers, A., Campoy, J., Wellington, C., 2012. Air-assisted sprayer adapted for precision horticulture: Spray patterns and deposition assessments in small-sized citrus canopies. Biosyst. Eng. 113, 76-85. doi:10.1016/j.biosystemseng.2012.06.008.

Landers, A.J., Balsari, P., Gil, E., 2012. Putting the spray onto the target - The development and demonstration of vertical patternation for fruit growers. In: ASABE Annual International Meeting, 29 July-1 August 2012, Dallas, Texas. doi:10.13031/2013.41703.

Llop, J., Gil, E., Gallart, M., Contador, F., Ercilla, M., 2015. Spray distribution evaluation of different setting of a hand-held trolley sprayer used in greenhouse tomato crops. Pest Manag. Sci. doi:10.1002/ps.4014.

Llorens, J., Gil, E., Llop, J., Escolà, A., 2010. Variable rate dosing in precision viticulture : Use of electronic devices to improve application efficiency. Crop Prot. 29, 239-248. doi:10.1016/j.cropro.2009.12.022.

Mandow, A., Gómez-de-Gabriel, J.M., Martínez, J.L., Muñoz, V.F., Ollero, A., García-Cerezo, A., 1996. The autonomous mobile robot AURORA for greenhouse operation. IEEE Robot. Autom. Mag. 3, 18-27. doi:10.1109/100.556479.

Murrell, P., 2005. R Graphics, Chapman and Hall/CRC.

Nilsson, E., Balsari, P., 2012. Testing of handheld equipment, testing in greenhouses, highlight problems and come up with common solutions. In: NiF Seminar 452: Testing and certification of agricultural machinery, Riga, Latvia. 
485 Nuyttens, D., Windey, S., Sonck, B., 2004a. Optimisation of a vertical spray boom for

486 greenhouse spray applications. Biosyst. Eng. 89, 417-423.

487 doi:10.1016/j.biosystemseng.2004.08.016.

488 Nuyttens, D., Windey, S., Sonck, B., 2004b. Comparison of operator exposure for five different 489 greenhouse spraying applications. J. Agric. Saf. Health 10, 187-195.

$490 \quad$ doi:10.13031/2013.16475.

491 Nuyttens, D., Braekman, P., Windey, S., Sonck, B., 2009. Potential dermal pesticide exposure

492 affected by greenhouse spray application technique. Pest Manag. Sci. 65, 781-790. 493 doi:10.1002/ps.1755.

494 Pai, N., Salyani, M., Sweeb, R.D., 2009. Regulating airflow of orchard airblast sprayer based on 495 tree foliage density. Trans. ASABE 52, 1423-1428.

496 Pergher, G., Gubiani, R., 1995. The effect of spray application rate and airflow rate on foliar 497 deposition in a hedgerow vineyard. J. Agric. Eng. Res. 61, 205-216.

498 doi:10.1006/jaer.1995.1048.

499 Pergher, G., Gubiani, R., Tonetto, G., 1997. Foliar deposition and pesticide losses from three air500 assisted sprayers in a hedgerow vineyard. Crop Prot. 16, 25-33. doi:10.1016/S0261$501 \quad 2194(96) 00054-3$.

502 Pergher, G., 2001. Recovery rate of tracer dyes used for spray deposit assessment. Trans. $503 \quad$ ASABE 44, 787-794. doi:10.13031/2013.6240. 
504 Pergher, G., Balsari, P., Cerruto, E., Vieri, M., 2002. The relationship between vertical spray 505 patterns from air-assisted sprayers and foliar deposits in vine canopies. Asp. Appl. Biology $506 \quad 66,323-330$.

507 Sammons, P.J., Furukawa, T., Bulgin, A., 2005. Autonomous pesticide spraying robot for use in 508 a greenhouse. In: Australasian Conference on Robotics and Automation, 5-7 December $509 \quad 2005$, Sidney, Australia.

510 Sánchez-Hermosilla, J., Rincón, V.J., Páez, F., Agüera, F., Carvajal, F., 2011. Field evaluation of 511 a self-propelled sprayer and effects of the application rate on spray deposition and losses to 512 the ground in greenhouse tomato crops. Pest Manag. Sci. 67, 942-947. 513 doi:10.1002/ps.2135.

514 Sánchez-Hermosilla, J., Rincón, V.J., Páez, F., Fernández, M., 2012. Comparative spray deposits 515 by manually pulled trolley sprayer and a spray gun in greenhouse tomato crops. Crop Prot. $516 \quad 31,119-124$. doi:10.1016/j.cropro.2011.10.007.

517 Sánchez-Hermosilla, J., Páez, F., Rincón, V.J., Carvajal, F., 2013. Evaluation of the effect of 518 spray pressure in hand-held sprayers in a greenhouse tomato crop. Crop Prot. 54, 121-125. 519 doi:10.1016/j.cropro.2013.08.006.

520 Siegfried, W., Viret, O., Huber, B., Wohlhauser, R., 2007. Dosage of plant protection products $521 \quad$ adapted to leaf area index in viticulture. Crop Prot. 26, 73-82.

522 doi:10.1016/j.cropro.2006.04.002. 
523 Subramanian, V., Burks, T.F., Singh, S., 2005. Autonomous greenhouse sprayer vehicle using 524 machine vision and ladar for steering control. Appl. Eng. Agric. 21, 935-943. 525 doi:10.13031/2013.19697.

526 van Os, E.A., Michielsen, J.M.G.P., Corver, F.J.M., van den Berg, J.V., Bruins, M.A., Porskamp, 527 H.A.J., van de Zande, J.C., 2005. Reduction of spray pressure leads to less emission and 528 better deposition of spray liquid at high-volume spraying in greenhouse tomato. Acta $529 \quad$ Hortic. (ISHS) 691, 187-194.

530 van Zuydam, R.P., van de Zande, J.C., 1996. Application technology, emission and safety in 531 glasshouse spraying. EPPO Bull. 26, 95-101. doi:10.1111/j.1365-2338.1996.tb01533.x.

532 Viret, O., Siegfried, W., Holliger, E., Raisigl, U., 2003. Comparison of spray deposits and 533 efficacy against powdery mildew of aerial and ground-based spraying equipment in 534 viticulture. Crop Protection 22, 1023-1032.

535 Zhou, J., He, X., Landers, A.J., 2012. Dosage adjustment for pesticide application in vineyards. 536 Trans. Asabe 55, 2043-2049. 
538 Table 1. Selected working parameters for field trials

\begin{tabular}{cccccccc}
\hline Treatment & Sprayer & $\begin{array}{c}\text { Air velocity } \\
\left(\mathrm{m} \mathrm{s}^{-1}\right)^{*}\end{array}$ & $\begin{array}{c}\text { Application } \\
\text { rate }\left(\mathrm{L} \mathrm{ha}^{-1}\right)\end{array}$ & $\begin{array}{c}\text { Forward speed } \\
\left(\mathrm{km} \mathrm{h}^{-1}\right)\end{array}$ & $\begin{array}{c}\text { Flow rate } \\
\left(\mathrm{L} \mathrm{min}^{-1}\right)\end{array}$ & $\begin{array}{c}\text { Number of } \\
\text { nozzles }\end{array}$ & $\begin{array}{c}\text { Pressure } \\
\left(\times 10^{2} \mathrm{kPa}\right)\end{array}$ \\
\hline T1 & Modified sprayer & 19.34 & 819.2 & 3.57 & 0.97 & 10 & 2.0 \\
T2 & Modified sprayer & 14.00 & 802.3 & 3.64 & 0.97 & 10 & 2.0 \\
T3 & Sagevi & 31.3 & 784.8 & 3.66 & 1.20 & 8 & 3.0 \\
T4 & Unigreen & 10.08 & 612.9 & 3.32 & 0.85 & 8 \\
\hline
\end{tabular}

* mean of air velocities measured with a portable impeller anemometer at each sprayer outlet

540 Table 2. Canopy characterisation values

541

\begin{tabular}{lc}
\hline Parameter & Value \\
\hline Row width $(\mathrm{m})$ & 2.00 \\
Canopy height $(\mathrm{m})$ & 1.96 \\
Canopy width $(\mathrm{m})$ & 1.07 \\
LAI & 5.46 \\
$\mathrm{LWA}^{\mathrm{a}}\left(\mathrm{m}^{2}{ }_{\text {vegetation }} \mathrm{ha}^{-1}\right)$ & 19600 \\
$\mathrm{TRV}^{\mathrm{b}}\left(\mathrm{m}^{3}{ }_{\text {vegetation }} \mathrm{ha}^{-1}\right)$ & 10486 \\
$\mathrm{LAD}^{\mathrm{c}}\left(\mathrm{m}^{2}{ }_{\text {leaves }} \mathrm{m}^{-3}\right.$ canopy $)$ & 5.21 \\
\hline${ }^{\mathrm{a}}$ Leaf wall area; ${ }^{\mathrm{b}}$ Tree row volume; ${ }^{\text {c }}$ Leaf area density
\end{tabular}


545 Table 3. Deposition and normalized deposition on canopy (mean \pm SEM), uniformity (measured by coefficient of variation), and

546 losses to the ground (mean \pm SEM)

\begin{tabular}{cccccc}
\hline Treatment & $\begin{array}{c}\text { Actual tracer } \\
\text { concentration } \\
\left(\mathrm{g} \mathrm{L}^{-1}\right)\end{array}$ & $\begin{array}{c}\text { Canopy } \\
\text { deposition } \\
\left(\mu \mathrm{g} \mathrm{cm}^{-2}\right)\end{array}$ & $\begin{array}{c}\text { Canopy normalized } \\
\text { deposition } \\
\left(\mu \mathrm{g} \mathrm{cm}^{-2} \text { leaf } / \mu \mathrm{g} \mathrm{cm}_{\text {ground }}\right),\end{array}$ & $\begin{array}{c}\text { Coefficient of } \\
\text { variation of canopy } \\
\text { deposits }(\%)\end{array}$ & $\begin{array}{c}\text { Ground losses } \\
\left(\mu \mathrm{g} \mathrm{cm}_{2}^{-2} \text { leaf } / \mu \mathrm{cm}^{-}\right. \\
\text {ground })\end{array}$ \\
\hline T1 & 10.16 & $17.24 \pm 1.335$ & $0.16 \pm 0.013 \mathrm{~b}$ & 77.0 & $0.118 \pm 0.0330 \mathrm{a}$ \\
$\mathrm{T} 2$ & 11.02 & $23.79 \pm 1.954$ & $0.20 \pm 0.014 \mathrm{a}$ & 69.7 & $0.139 \pm 0.0360 \mathrm{a}$ \\
$\mathrm{T} 3$ & 12.16 & $18.12 \pm 1.897$ & $0.14 \pm 0.010 \mathrm{bc}$ & 78.1 & $0.158 \pm 0.0211 \mathrm{a}$ \\
$\mathrm{T} 4$ & 13.42 & $12.28 \pm 1.250$ & $0.11 \pm 0.010 \mathrm{c}$ & 91.4 & $0.207 \pm 0.0447 \mathrm{a}$ \\
\hline
\end{tabular}

547

Different letters (in columns) represent significant differences $(\mathrm{P}<0.05)$

548

549 Table 4. Normalized deposition at external and internal side of the canopy $\left(d_{n}\right)$.

\begin{tabular}{ccc}
\hline Treatment & $\begin{array}{c}d_{n} \text { external side } \\
\left(\mu \mathrm{g} \mathrm{cm}^{-2} \text { leaf } / \mu \mathrm{g} \mathrm{cm}_{\text {ground }}\right)\end{array}$ & $\begin{array}{c}d_{n} \text { internal side } \\
\left(\mu \mathrm{g} \mathrm{cm}^{-2}{ }_{\text {leaf }} / \mu \mathrm{g} \mathrm{cm}^{-2} \text { ground }\right)\end{array}$ \\
\hline T1 & $0.24 \pm 0.018 \mathrm{~b}$ & $0.08 \pm 0.010 \mathrm{ab}$ \\
T2 & $0.32 \pm 0.026 \mathrm{a}$ & $0.11 \pm 0.012 \mathrm{a}$ \\
T3 & $0.22 \pm 0.027 \mathrm{~b}$ & $0.08 \pm 0.008 \mathrm{ab}$ \\
T4 & $0.19 \pm 0.019 \mathrm{~b}$ & $0.05 \pm 0.007 \mathrm{~b}$ \\
\hline
\end{tabular}

550

Different letters (in columns) represents significant differences $(\mathrm{p}<0.05)$

551

552

553 

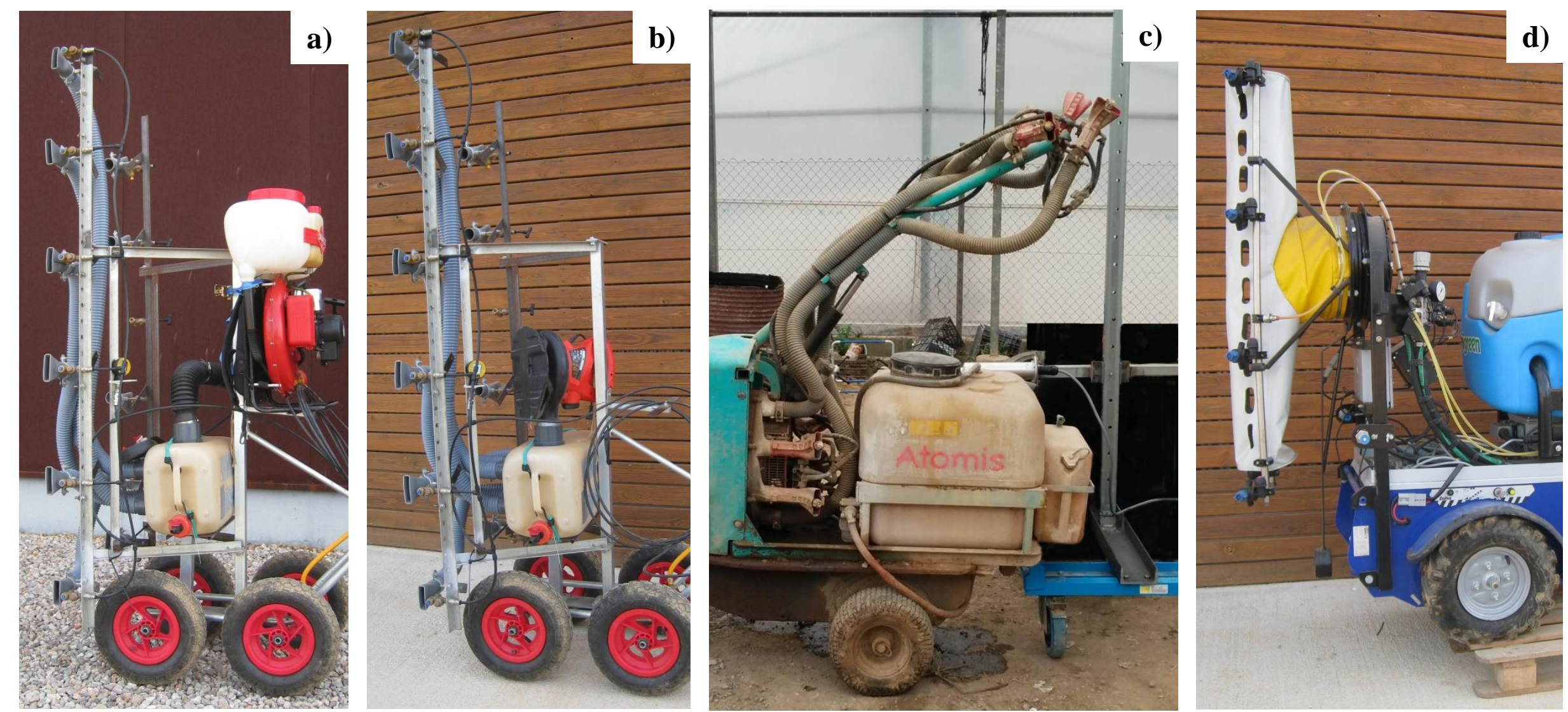


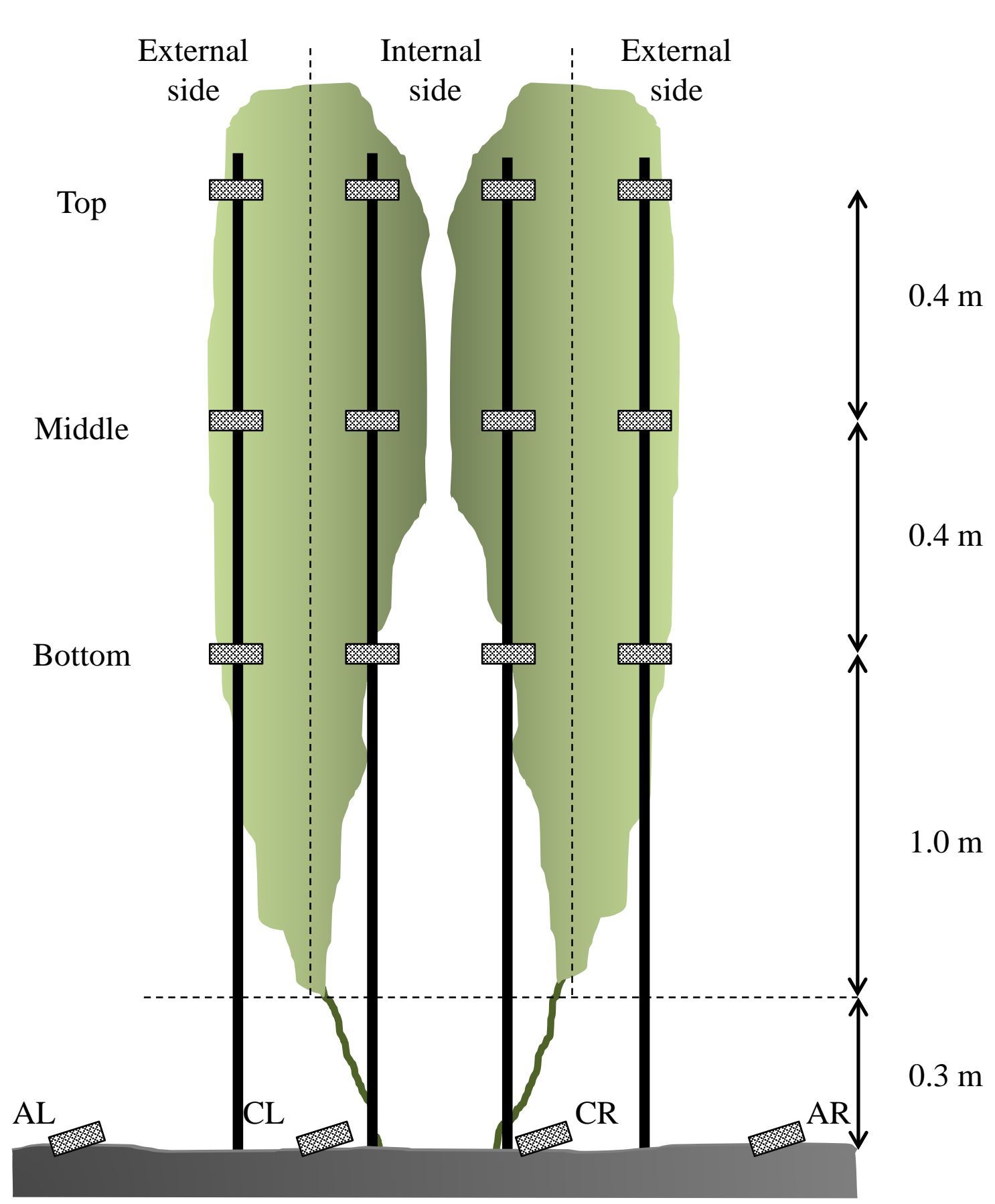



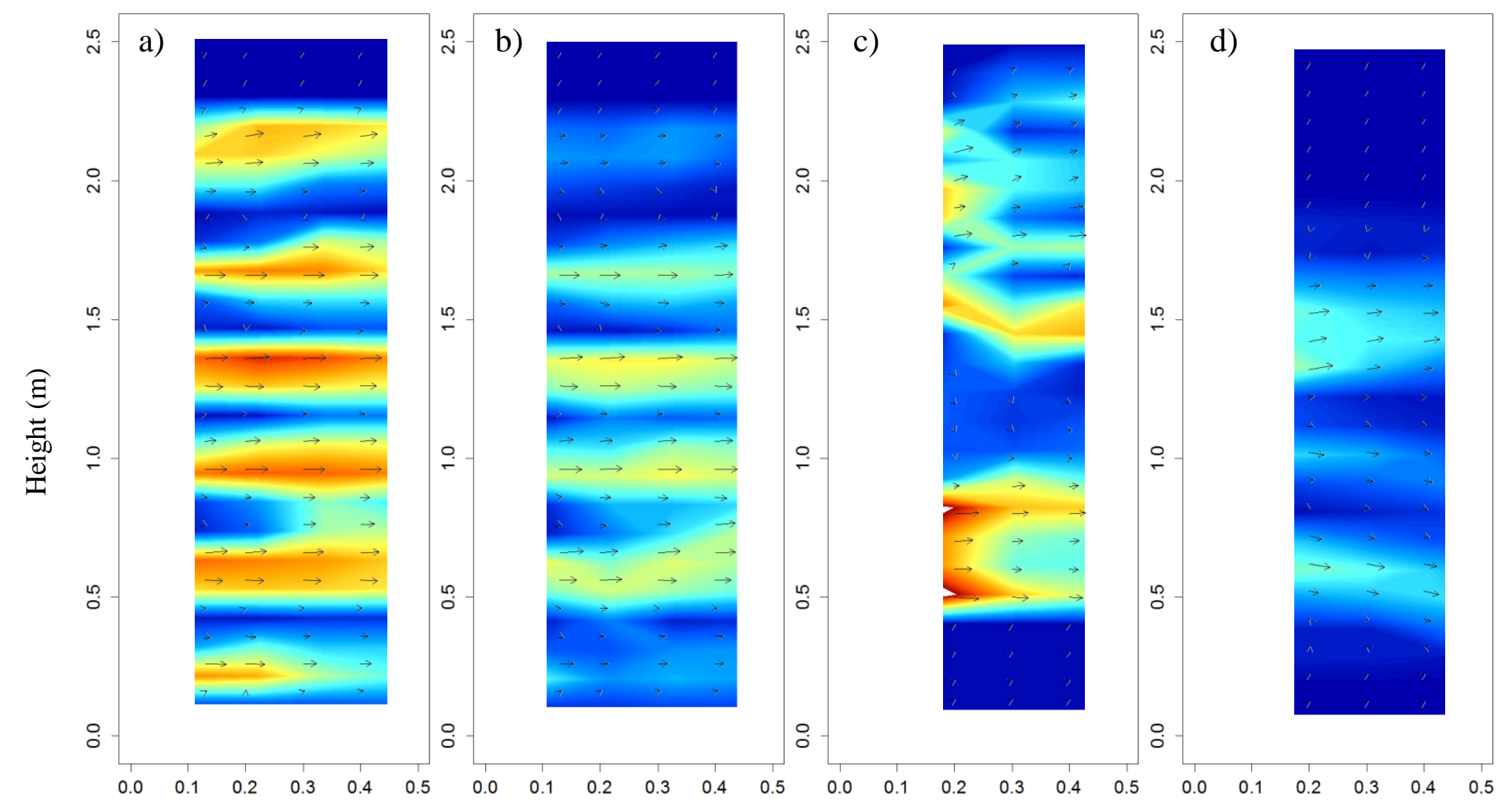

$5 \mathrm{~m} \cdot \mathrm{s}^{-1} \longrightarrow$
$4 \mathrm{~m} \cdot \mathrm{s}^{-1} \longrightarrow$
$3 \mathrm{~m} \cdot \mathrm{s}^{-1} \rightarrow$
$2 \mathrm{~m} \cdot \mathrm{s}^{-1} \rightarrow$
$1 \mathrm{~m} \cdot \mathrm{s}^{-1} \rightarrow$



Distance from air outlet (m) 
Figure4

\section{FIGURE 4}
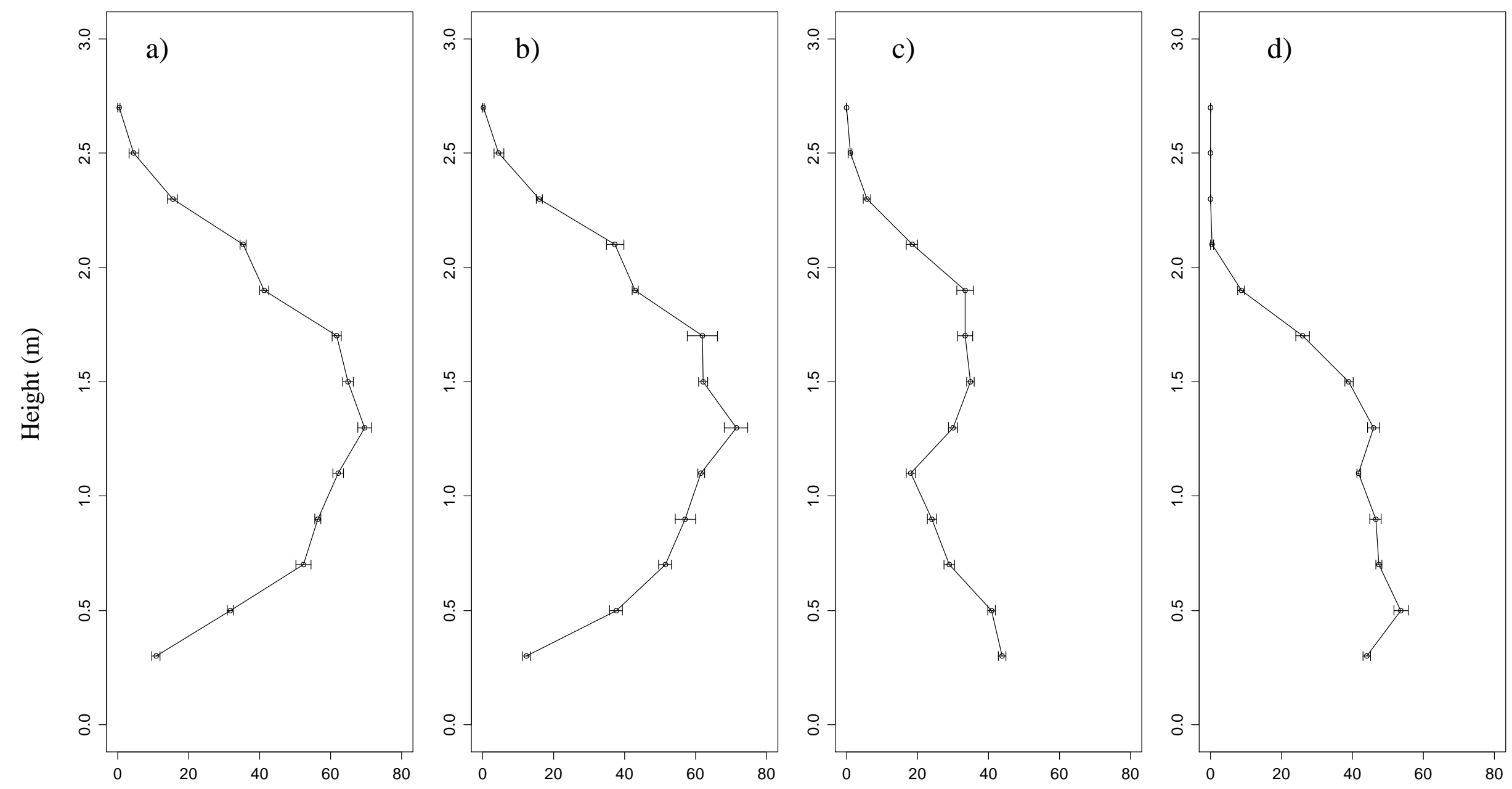

Liquid recovery (\%) 





Figure6

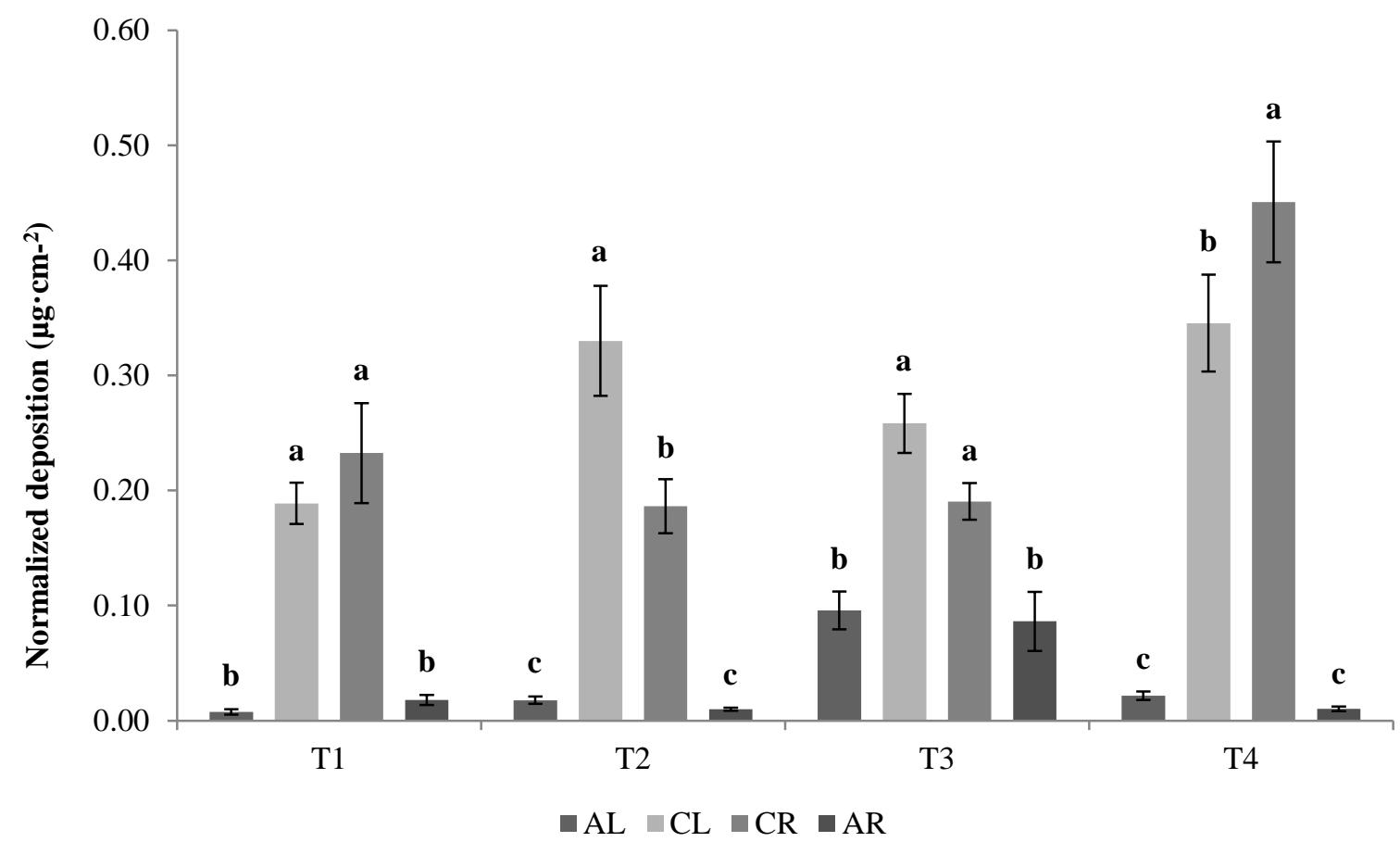




\section{Highlights}

- A hand held trolley with air assistance was tested for greenhouse spray application.

- The best depositions results were obtained with an air speed of $14 \mathrm{~m} \mathrm{~s}^{-1}$.

- Increasing air velocity did not result in an increase in canopy deposition.

- The vertical patternator was a valuable tool to assess canopy deposition distribution. 